\title{
Loa «Escuche mi voz el orbe» de sor Juana Inés de la Cruz: edición crítica
}

\section{Loa «Escuche mi voz el orbe» by sor Juana Inés de la Cruz. Critical edition}

\author{
J. Enrique Duarte \\ ORCID ID: 0000-0002-5556-3025 \\ Universidad de Navarra, GRISO \\ ESPAÑA \\ eduarte@unav.es
}

[Hipogrifo, (issn: 2328-1308), 6.2, 2018, pp. 553-579]

Recibido: 14-08-2018 / Aceptado: 11-09-2018

DOI: http://dx.doi.org/10.13035/H.2018.06.02.41

Resumen. El autor de este artículo presenta la edición crítica de la loa de sor Juana Inés de la Cruz «Escuche mi voz el orbe». Se han tenido en cuenta cinco testimonios, que han permitido establecer con garantías un texto crítico, mostrando que esta loa tiene una historia textual diferente a otras de la misma autora. La edición va acompañada de una anotación que indica sus claves y facilita la compresión del texto. Además de la edición, se muestra la estructura métrica.

Palabras clave. Sor Juana Inés de la Cruz; loa «Escuche mi voz el orbe»; edición crítica; anotación; estructura; métrica.

Abstract. The author presents a new critical edition of a «Loa» by sor Juana «Escuche mi voz el orbe». The edition is composed using five testimonies, showing that this Loa has a different textual history compared to other works by sor Juana. The edition is also provided with a precise annotation to clarify the passages of more complexity and facilitate its understanding.

Keywords. Sor Juana Inés de la Cruz; Loa «Escuche mi voz el Orbe»; Critical Edition; Annotation; Structure; Metrics. 


\section{INTRODUCCIÓN: ATRIBUCIÓN Y FECHA}

La loa de sor Juana Inés de la Cruz «Escuche mi voz el orbe» presenta un panorama textual bastante diferente al acostumbrado en otras loas. No obstante, parece que esta pieza no presenta dudas de autoría como explica Méndez Plancarte en el tercer volumen de las Obras completas, quien la relaciona con la loa «Aunque de la vida son»?:

Al igual que la loa anterior, saluda a los Marqueses de la Laguna, sin aludir todavía a su hijito. Esta y aquella, pues, deben fecharse el 6 de noviembre de 1681 y 82, quedando incierto el año de cada cual².

\section{MÉTRICA Y RESUMEN ARGUMENTATIVO}

vv. 1-98:

Romance en agudas. La loa se abre con dos coros que cantan dentro (vv. 1-6 y 7-12 con versos octosílabos y dodecasílabos) celebrando que ese día es el del sol y el mayor día que el Cielo formó. El Tiempo sale (vv. 13 y ss.) preguntándose cómo es posible que, siendo 6 de noviembre y uno de los días más cortos del año, la música insista continuamente en esa idea (pasajes cantados en los versos 40-41, 49-50, 68-69) y pide ayuda para que alguien le alumbre en su ciega confusión. Salen los personajes del Cielo y el Sol (vv. 97-98) como voluntarios para explicar los misterios de ese día.

vv. 99-126 Endechas reales. Mezcla de versos heptasilabos y endecasílabos en los que el Tiempo se dirige al Cielo y al Sol y estos le piden que escuche la música de las esferas.

vv. 127-142 Romance é-o. La música de los Coros le comunica al dudoso Tiempo que es el día del natalicio del rey Carlos II, por lo que el día no es largo por la extensión, sino por el privilegio de haber nacido el rey en esa fecha. Dentro de la respuesta de los dos coros encontramos dos pasajes cantados (vv. 131-134 y 139-142 con una métrica irregular y rima en á-e).

vv. 143-156 Romance ú-a: el Cielo y el Sol consideran solucionadas las dudas, pero el Tiempo insiste, necesitando que expliquen mejor la situación.

vv. 157-168 Romance en aguda: la Música se esfuerza en ofrecerle argumentos: Carlos II es un luminar más hermoso y sus rayos deslucen el Sol material.

1. Ver la edición crítica de la loa, Duarte, 2017.

2. Sor Juana, Obras completas, ed. Méndez Plancarte, vol. 3, p. 664. Ver también Poot Herrera, 2014, pp. 27-28, donde realiza un inventario de las loas y habla de esta en los siguientes términos: «"Loa a los años del Rey [III]" (376; II, p. 351; 449 vs.); "Escuche mi voz el orbe". Podría situarse el 6 de noviembre de 1681 o 1682. El rey cumpliría 20 o 21 años. El hijo de los virreyes aún no había nacido (nace en julio de 1683). Ya con esta loa se marcaba una tradición de loar año con año al joven monarca, hijo de una reina que tenía cerca de ella a personajes que conocieron, leyeron y admiraron a sor Juana Inés de la Cruz, la autora más puntual en las alabanzas de aniversarios cortesanos». 
vv. 169-189 Pasaje de estructura métrica compleja. Para Méndez Plancarte, se trata de una: «Rara estructura estrófica. Quintetos de versos de 8 y tres versos de 11, aconsonantados con este esquema: "a-b-B-A-A"; y tras cada uno de ellos, un pareado de 5 y de 11 ó 12, con una misma asonancia» ${ }^{3}$.

La Música, el Cielo y el Sol insisten en sus argumentos y piden al Tiempo que se deje convencer para no ser obstinado. Al final, el Tiempo queda convencido.

vv. 190-233 Romance é-0: con una estructura semejante a las endechas reales, con tres versos octosílabos o heptasílabos y un verso endecasílabo ${ }^{4}$. Para celebrar el natal de Carlos II, los personajes van a iniciar las celebraciones cantando, insertando en los versos 206 al 211 versos hexasílabos con la misma rima del romance.

vv. 234-317 Romance é-a: en combinación con pasajes cantados con otros metros aunque con la misma rima. La Juventud quiere parar la fiesta porque en lugar de felicitar al rey, están celebrando sus grandezas. A esta objeción responde el Tiempo, advirtiendo que festejar las excelencias del rey no se escapa del asunto de los años. La Prudencia aparece avisando que rige todas las acciones del joven monarca. A esta le sigue la Felicidad, ya que si la Prudencia es la que manda, las consecuencias serán felices. Los argumentos del Tiempo, Prudencia y Felicidad están subrayados por pasajes cantados con una combinación de cuatro versos heptasílabos y pentasílabos en los versos 268-271, 296-299 y 314-317.

vv. 318-449 Romance í-e: todos los personajes celebran los años del rey y se inicia el recuerdo de los grandes personajes de la corte: la Prudencia elogia a la reina francesa, María Luisa de Orleans, el Cielo celebra a la reina madre, Mariana de Austria, y la Felicidad invoca al virrey y a su consorte a los que celebran el Sol y el Cielo. Se acaba la loa con las alabanzas al público, a la ciudad y a las damas y su belleza. Encontramos pasajes cantados de versos pentasílabos y endecasílabos con la misma rima del romance en los versos 326-331, 366-369, 390-393 finalizando la loa con un pasaje cantado en versos dodecasílabos con la misma rima (vv. 446-449).

\section{ESTUDIO TEXTUAL}

A diferencia de otras ediciones de las loas de sor Juana que he publicado ${ }^{5}$, el texto de «Escuche mi voz el orbe» se encuentra en cinco testimonios, cuyos datos y siglas aporto en el apartado dedicado a las variantes. Méndez Plancarte enumera alguno de los testimonios en los que aparece esta loa6, aunque yo he podido

3. Ver sor Juana Inés, Obras completas, vol. 3, p. 668.

4. En esa estructura es necesario el verso 219 para regularizar esa combinación de tres versos octosílabos o heptasílabos más un verso endecasílabo y que los originales han perdido.

5. Ver Duarte y Oteiza, 2012; Duarte, 2012; 2017a y 2017 b.

6. Ver Obras completas, ed. Méndez Plancarte, vol. 3, p. 664: «II, 1692, 351; 1693, 275; 1725, 255». 
encontrar esta loa en las páginas de otro testimonio: las Obras poéticas de la musa mexicana de 1715.

\subsection{MP frente al resto de testimonios}

Hay una serie de variantes que separan la edición moderna realizada por Méndez Plancarte frente al resto de testimonios y que merecen ser comentadas.

MP

$\begin{array}{ll}6 & \text { propio día del sol } \\ 46 & \text { no lo corrige } \\ 48 & \text { del día repite } \\ 54 & \text { menor mal + E8 } \\ 67 & \text { lo llama } \\ 74 & \text { lo llama } \\ 152 & \text { la dificultan } \\ 219 & \text { Del mayor monarca, del sol Hesperio } \\ 253 & \text { consejo les debas } \\ 344 & \text { al noble } \\ 449 & \text { gran monarca viva, viva }\end{array}$

SV, ST, OP y E8

proprio dia del sol

no le corrija

del día repita

menos mal

se llama

le llama

las dificultan

omite

consejo le debas

el noble

gran monarcha viva, viva, viva

En primer lugar, podemos decir que las lecturas de los versos 46 y 48 son un poco confusas en los testimonios antiguos (el sol desmiente que los días sean tan largos en septiembre), por lo que el modo del verbo en indicativo me parece más apropiado para estos dos pasajes. En el verso 54 encontramos otra variante similar pues la lectura de MP es mejor que la del resto de testimonios, mientras que en el verso 67 mantengo la lectura de la princeps. Creo que el v. 152 muestra un error en todos los testimonios salvo MP (la lectura de la edición moderna es más clara), muy parecido al que encontramos en el verso 253 , aunque en este caso prefiero la lectura de SV. En el verso 219, MP introduce un verso que es necesario para el equilibro de la estructura métrica, como he tratado de demostrar en el apartado anterior dedicado a la métrica. En el verso 344, la lectura que ofrece la edición de Méndez Plancarte es más apropiada y en el verso 449 SV, ST y OP añaden dos sílabas más, por lo que prefiero también la lectura de la última edición que sigue la disposición semejante del verso 331.

Otras variantes tienen más que ver con la forma de la lengua en siglo XVII. La variante del verso 6 muestra una modernización de MP en el término proprio que prefiero respetar ${ }^{7}$ y que afecta también a otros versos (41, 69 y 251). De igual manera, mantengo la forma típica de la lengua del XVII en otras expresiones como

7. Proprio es la forma etimológica de proprium, muy corriente en el Siglo de Oro. La moderna propio también era usual en el siglo XVII, pero aquí respeto las lecturas de la príncipe. Ver Calderón, El divino Jasón, n. a v. 158. 
reduzga (v. 154), asumpto en lugar de asunto (vv. 234, 258, 297 y 442) o esempto en lugar de exento (v. 297).

MP muestra una tendencia, como se ha podido ver en otras loas que he editado, a una sustitución del pronombre le por lo $(74,118,139$ y 198) que no sigo, respetando la forma que presenta SV.

Por último, tengo que recordar que la edición de Méndez Plancarte divide el texto en escenas (vv. 1, 96, 142, 201, 233, 271, 299, 317) y que ignoro tal división.

\section{Testimonios SV, ST, OP y E8}

Un rápido análisis de las lecturas proporcionadas por el aparato de variantes nos demuestra que SV es el modelo de las dos ediciones posteriores ST y OP. Si se revisa con cierto cuidado las ediciones de SV y ST se verá que ST es una copia a plana y reglón de SV y que OP coincide con la disposición de ST incluso en el número de las páginas. No ocurre lo mismo con E8 cuya disposición tipográfica es bastante diferente a los anteriores testimonios.

Por su parte, ST presenta lecturas propias que el resto de testimonios corrigen en el verso 105 (error al duplicar una preposición en) y el verso 333 (donde prefiero la lectura del resto de testimonios).

En cuanto a OP, no resulta modelo de las otras ediciones por la fecha en la que fue publicada y por una serie de lecturas propias en los versos 180 (lectura equipolente), 294 (donde encontramos una pequeña errata) y el 395 con un caso semejante (donde la lectura de este testimonio rompe el sentido del verso).

El caso de E8 es particular, pues no presenta variantes propias y sigue la edición de SV, no copiando lecturas de ST ni OP, por lo que debemos pensar que procede de la princeps. La única desviación se produce en el verso 54 ya que corrige la lectura de la príncipe y coincide con MP.

Teniendo en cuenta estos datos extraídos del aparato de variantes, propongo el siguiente estema para esta loa:

8. Ver Alatorre, 2003, pp. 506 y 507: «Merece una consideración el uso de los pronombres le, la y lo en el español de sor Juana. Pedro Henríquez Ureña (citado por MP en nota a 4:107) afirma que ella distinguía entre el lo acusativo y el le dativo, "como se ha hecho siempre en América" (en el español americano no prosperaron ni el leísmo ni el laísmo), y que los casos de le acusativo y la dativo que hay en su obra "se deben a los impresores europeos"» (506). Pero para Alatorre, no es tan claro que sor Juana no cometiese leísmos y laísmos: «creo que así como en una edición crítica debe respetarse - salvo erratas evidentesel texto de las fuentes primarias, así hay que dejar tal cual la vacilación de le, lo, la, que refleja la realidad de la lengua a fines del siglo XVII». 


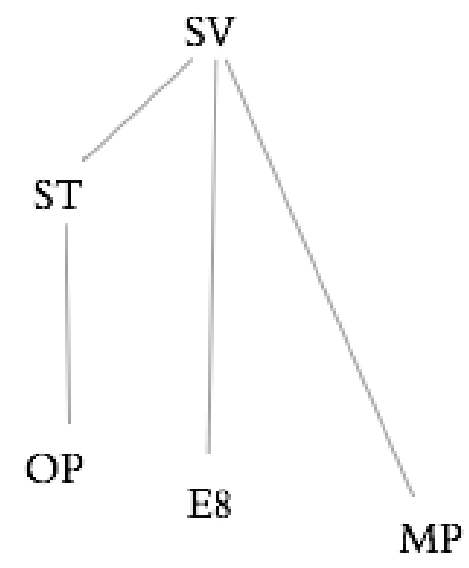

En definitiva, para esta edición, realizo una edición ecléctica partiendo del texto base que proporciona SV (Segundo volumen de las obras de soror Juana Inés de la Cruz) al que añadimos distintas variantes propuestas por los otros testimonios, especialmente MP. Resumiendo, corrijo las lecturas de los versos 46 y 48 (que considero errónea la lectura de SV, ST y OP) y admito la lectura de MP en el verso 54, 67, 219, 344 y 449 por las razones que he aportado en el estudio textual. También ignoro la división en escenas que realiza la edición de Méndez Plancarte.

En esta edición sigo también los criterios propuestos por el equipo de investigación GRISO, ateniéndome a los criterios que para las obras de sor Juana ha marcado Ignacio Arellano en sus artículos ${ }^{9}$. Modernizamos grafías que no tienen relevancia fonética, respetando aquellos términos con una pronunciación ligeramente diferente en la época de sor Juana (reduzga, asumpto, propria, esempto). Regularizamos el empleo de mayúsculas y acentos según la práctica actual y los nombres de los locutores los desarrollamos y regularizamos. En el caso de cancioncillas, estribillos, etc., muy frecuentes en el teatro áulico en general, y especialmente en las loas de sor Juana, que se copian en las impresiones de forma abreviada, las desarrollamos completas, numerando los versos reales que se pronuncian en la representación teatral. Anotamos todos aquellos aspectos que pueden aclarar el sentido de los pasajes dificultosos para que el lector de este momento pueda entender correctamente la loa.

9. Ver, especialmente, Arellano, 2012, p. 16: «Me interesa señalar, simplemente, algunas orientaciones prácticas [...] adaptadas en este caso al proyecto de edición crítica de sor Juana, en el que está actualmente trabajando un amplio equipo internacional coordinado por el Grupo de Investigación Siglo de Oro de la Universidad de Navarra». 


\section{BiBLIOgRAFÍA}

Agustín de Hipona, san, La ciudad de Dios; Vida de san Agustín, ed. Santos Santamarta del Río, et al., Madrid, Biblioteca de Autores Cristianos, 2013.

Alatorre, Antonio, «Hacia una edición crítica de sor Juana», Nueva Revista de Filología Hispánica, LI, 2, 2003, pp. 439-526.

Arellano Ayuso, Ignacio, «A propósito de sor Juana Inés de la Cruz y la edición de textos del Siglo de Oro», Taller de Letras, NE1, 2012, pp. 15-32.

Bances Candamo, Francisco Antonio, Teatro de los teatros de los pasados y presentes siglos, ed. Duncan W. Moir, London, Tamesis Books, 1970.

Calderón de la Barca, Pedro, El año santo de Roma, ed. Ignacio Arellano y Ángel L. Cilveti, Pamplona / Kassel, Universidad de Navarra / Reichenberger, 1995.

Calderón de la Barca, Pedro, El divino Jasón, ed. Ignacio Arellano y Ángel L. Cilveti, Pamplona / Kassel, Universidad de Navarra / Reichenberger, 1992.

Calderón de la Barca, Pedro, El divino Orfeo, ed. J. Enrique Duarte, Pamplona / Kassel, Universidad de Navarra / Reichenberger, 1999.

Calderón de la Barca, Pedro, El gran mercado del mundo, ed. Ana Suárez Miramón, Pamplona / Kassel, Universidad de Navarra / Reichenbeger, 2003.

Calderón de la Barca, Pedro, El nuevo hospicio de pobres, ed. Ignacio Arellano, Pamplona / Kassel, Universidad de Navarra / Reichenberger, 1995.

Calderón de la Barca, Pedro, En la vida todo es verdad y todo mentira, en Comedias. 3: tercera parte de Comedias, ed. Donald W. Cruicksank, Madrid, Fundación José Antonio de Castro, 2006, pp. 17-144.

Camos, Marco Antonio, Microcosmía y gobierno universal del hombre cristiano para todos los estados y cualquiera de ellos. Dirigido a don Antonio de Cardona, duque de Sessa y Soma, del Consejo del Rey nuestro señor y por su majestad embajador de España en Roma. Va por diálogos dividido en tres partes. En la primera se trata de las personas reales y de su gobierno de paz y guerra, consejos y ministros. En la segunda, del gobierno político, magistrados y personas ocupadas en ellos; y de la Economía y estados a la República necesarios. En la tercera y última de la Monarquía eclesiástica y personas de este estado y religiosos, Barcelona, Pablo Malo, 1592.

Canisio, Pedro, Doctrina cristiana, ed. Rafael Zafra, Palma de Mallorca, José J. de Olañeta, 2014.

Carranza, Bartolomé de, Comentarios sobre el catechismo christiano, ed. José Ignacio Tellechea Idígoras, Madrid, Editorial Católica, 1972, 3 vols.

Covarrubias Horozco, Sebastián de, Tesoro de la lengua castellana o española, ed. Ignacio Arellano y Rafael Zafra, Madrid / Frankfurt am Main, Iberoamericana / Vervuert, 2006. 
Duarte, J. Enrique y Blanca Oteiza, «Loa Al luminoso natal de sor Juana Inés de la Cruz: Edición crítica», Taller de Letras, NE 1, 2012, pp. 95-137.

Duarte, J. Enrique, «Loa Si la tórrida de sor Juana Inés de la Cruz: Edición crítica», Taller de Letras, NE 1, 2012, pp. 63-94.

Duarte, J. Enrique, «Sor Juana Inés de la Cruz. Loa "Hoy, al clarín de mi voz"», en «Estos festejos de Alcides». Loas sacramentales y cortesanas del Siglo de Oro, ed. Carlos Mata Induráin, New York, IDEA, 2017a, pp. 169-200.

Duarte, J. Enrique, «Sor Juana Inés de la Cruz. Loa "Aunque de la vida son"», en «Estos festejos de Alcides». Loas sacramentales y cortesanas del Siglo de Oro, ed. Carlos Mata Induráin, New York, IDEA, 2017b, pp. 201-233.

Fernández de Medrano, Sebastián, Breve descripción del mundo y sus partes o guía geográfica y hidrográfica, dividida en tres libros, Bruselas, Herederos de Francisco Foppens, 1686.

García Valdés, Carmen Celsa, «La Biblia en la obra literaria de sor Juana Inés de la Cruz», en La Biblia en la literatura del Siglo de Oro, ed. Ignacio Arellano y Ruth Fine, Madrid / Frankfurt am Main, Iberoamericana / Vervuert, 2010, pp. 168-189.

Gracián, Baltasar, El Criticón, ed. Miguel Romera-Navarro, Philadelphia, University of Pennsylvania Press, 1938-1940, 3 vols.

Grimal, Pierre, Diccionario de mitología griega y romana, Barcelona, Paidós, 1989.

Isidoro de Sevilla, san, Etimologías, 2. (Libros XI-XX), ed. José Oroz Reta y ManuelAntonio Marcos Casquero, Madrid, Biblioteca de Autores Cristianos, 1983.

Juana Inés de la Cruz, sor, Obras completas de sor Juana Inés de la Cruz, ed. Alfonso Méndez Plancarte, México, Fondo de Cultura, 1951-1955, 3 vols.

Lapesa, Rafael, Historia de la lengua española, Madrid, Gredos, 1988.

Long, Pamela H., Sor Juana / Música: How the Décima Musa Composed, Practiced and Imagined Music, Nueva York, Peter Lang, 2009.

Macarte y Díaz, Dionisio, Lecciones de navegación o principios necesarios a la ciencia del piloto, Madrid, Imprenta de Sancha, 1801.

Manero Sorolla, Ma . Pilar, Imágenes petrarquistas en la lírica española del Renacimiento: repertorio, Barcelona, PPU, 1990.

Maravall, José Antonio, Teoría del estado en España en el siglo XVII, Madrid, Centro de Estudios Constitucionales, 1997.

Martínez, Henrico, Repertorio de los tiempos y historia natural desta nueva España, México, Imprenta de Henrico Martínez, 1606.

Márquez, Juan, El gobernador cristiano deducido de la vida de Josué, príncipe del pueblo de Dios, Madrid, Imprenta y librería de don Manuel Martín, 1773. 
Pérez de Moya, Juan, Philosofía secreta de la gentilidad, ed. Carlos Clavería Arza, Madrid, Cátedra, 1995.

Poot Herrera, Sara, «La poesía inicial de sor Juana ya en el "virreinato de filigrana"», Anthropos: cuadernos de cultura crítica y conocimiento. Dedicado a: sor Juana Inés de la Cruz. La construcción de lo femenino en su obra «menor». Los mundos cortesano y festivo de loas y villancicos, 243, 2014, pp. 15-32.

Real Academia Española, Diccionario de Autoridades, Madrid, Gredos, 1990, 3 vols.

Real Academia Española, Banco de datos (CORDE) [en línea]. Corpus diacrónico del español. <http://www.rae.es>

Real Academia Espanola, Diccionario de la lengua española, Madrid, 2017.

Ripa, Cesare, Iconología. Tomos I y II, Madrid, Akal, 2002.

Saavedra Fajardo, Diego de, Empresas políticas, ed. Sagrario López Poza, Madrid, Cátedra, 1999.

Séneca, Lucio Aneo, Epístolas morales a Lucilio, I: Libros I-IX, epístolas 1-80, ed. Antonio Fontán e Ismael Roca Meliá, Barcelona, RBA Editores, 2008.

Suárez de Figueroa, Cristóbal, Plaza universal de todas ciencias y artes, ed. Mauricio Jalón, Valladolid, Junta de Castilla y León, Consejería de Cultura y Turismo, 2006, 2 vols.

Tosca, Tomás Vicente, Compendio matemático en que se contienen todas las materias más principales de las ciencias que tratan de la cantidad. Tomo VII que contiene la astronomía, Madrid, Imprenta de Antonio Marín, 1727.

Vitoria, Baltasar de, Primera parte del teatro de los dioses de la gentilidad, Valencia, Herederos de Crisóstomo Garriz, 1646. 


\title{
TEXTO DE LA LOA «ESCUCHE MI VOZ EL ORBE» DE SOR JUANA INESS DE LA CRUZ
}

\author{
INTERLOCUTORES
}

SOL

PRUDENCIA

CIELO

JUVENTUD

TIEMPO

FELICIDAD

\section{(Cantan dentro)}

CORO 1 Escuche mi voz el orbe y sépase que en mí es hoy toda armonía la luz, todo voces el ardor. ¡Suene mi voz, pues hoy es el más proprio día del Sol!

CORo 2 Aunque yo, en medir los días, árbitro supremo soy, distribuyendo mis giros el pequeño y el mayor, ¡sepan que hoy es el mayor día que el Cielo formó!

(Sale el Tiempo.)

vv. 9-10 giros / el pequeño y el mayor: se trata de los dos movimientos de la tierra, el de rotación y el de translación. Se trata del día y del año respectivamente. Ver Fernández Medrano, Breve, pp. 313-314: «Año es espacio de doce meses que comprehenden trescientos y sesenta y cinco días y seis horas que, como he dicho es lo que tarda el sol en rodear o dar una vuelta a la eclíptica». Ver también Fernández Medrano, Breve, p. 314: «El día es natural o artificial; este se entiende por lo que está el sol sobre el horizonte, como desde que nace hasta que muere; y el otro lo que tarda el primer móvil en dar su vuelta que son veinte y cuatro horas». Tosca, Compendio matemático, p. 43: «El movimiento diurno es aquel con el cual la tierra se mueve en espacio de 24 horas alrededor de su centro de poniente a levante, revolviéndose a sí misma. Movimiento anuo es aquel con que la tierra se mueve por la eclíptica de poniente a levante en espacio de un año, según el orden de los signos. El movimiento diurno de la tierra de poniente a levante hace parecer que el sol y estrellas se mueven en 24 horas de levante a poniente. Y el movimiento anuo de la misma tierra por la eclíptica de poniente a levante hace parecer que el sol se mueve con semejante movimiento». 


\begin{tabular}{|c|c|c|}
\hline TIEMPO & $\begin{array}{l}\text { ¿Qué dulces, sonoros ecos, } \\
\text { con métrica suspensión, } \\
\text { cuanto suenan al sentido } \\
\text { disuenan a la razón? } \\
\text { ¿Yo no soy el Tiempo, a quien } \\
\text { la omnipotencia le dió } \\
\text { en los giros de la esfera } \\
\text { tan noble generación? } \\
\text { ¿No soy yo quien forma el día, } \\
\text { o por decirlo mejor, } \\
\text { no soy yo a quien forma el día, } \\
\text { pues de él me compongo yo? } \\
\text { ¿No soy de su cuantidad } \\
\text { diligente observador? } \\
\text { ¿No sé cuál de ellos es más } \\
\text { asistido del farol } \\
\text { diurno y cuál goza menos } \\
\text { de su lúcida estación? } \\
\text { Pues siendo hoy seis de noviembre, } \\
\text { mes en que los días son } \\
\text { más cortos por la distancia } \\
\text { en que su ardiente esplendor } \\
\text { con lo que a una región quita } \\
\text { ilumina otra región, } \\
\text { ¿cómo escucho que el Sol mismo, } \\
\text { que es el que sabe mejor } \\
\text { aquesta verdad, entona...? }\end{array}$ & 25 \\
\hline MÚSICA Y SOL & $\begin{array}{l}\text { ¡Suene mi voz, } \\
\text { pues hoy es el más proprio día del Sol! }\end{array}$ & 40 \\
\hline TIEMPO & $\begin{array}{l}\text { Y el Cielo, que es el que solo } \\
\text { corregir puede el error } \\
\text { del Sol, si es que el error puede } \\
\text { tener lugar en el Sol, } \\
\text { no sólo no lo corrige, }\end{array}$ & 45 \\
\hline \multicolumn{3}{|c|}{$\begin{array}{l}\text { v. } 14 \text { métrica suspensión: como la expresión métrica armonía, que utiliza sor Juana en otras loas, } \\
\text { estamos ante una expresión enfática para designar el sonido de la música, que produce suspensión, y } \\
\text { que necesita orden, proporción y medida. Tomo la nota de El año santo de Roma, v. 14. Ver sor Juana, } \\
\text { Loa «Aunque de la vida», vv. 17-20: «iCon cuanta razón, oh grave, / métrica dulce armonía, / de tan alto } \\
\text { heroico asumpto / el alto timbre me aplicas». Ver también n. al v. 119, armonía. } \\
\text { v. } 19 \text { giros de la esfera: el movimiento de las esferas se produce en el tiempo y a lo largo de él. Ver } \\
\text { Martínez, Repertorio de los tiempos, s. p.: «De las ciencias humanas en que más el alma se recrea tiene } \\
\text { la astronomía el primer lugar [...] porque si se nota el uniforme y regular movimiento que cada uno de } \\
\text { los cielos y planetas guarda en su curso, así en tiempo como en lugar, se ve que va todo por un nivel tan } \\
\text { compasado que no lo traspasan jamás un punto, lo cual no solo recrea el alma, pero también mueve a } \\
\text { devoción». Para el tiempo que tardan en girar cada una de las diez esferas de la creación, ver Fernández } \\
\text { Medrano, Breve, pp. 32-33. Ver sor Juana, Loa «Hoy, al clarín», vv. 13-16: «Hoy, a la dulce armonía / de } \\
\text { mis bien templadas voces, / los orbes celestes paren / sus movimientos veloces». } \\
\text { v. } 35 \text { región: el movimiento de traslación hace que los días naturales sean en noviembre más cortos. }\end{array}$} \\
\hline
\end{tabular}




\begin{tabular}{|c|c|c|}
\hline \multirow[b]{2}{*}{ MÚSICA } & \multicolumn{2}{|l|}{$\begin{array}{l}\text { mas, celebrando el blasón } \\
\text { también del día repite: }\end{array}$} \\
\hline & $\begin{array}{l}\text { ¡Sepan que hoy } \\
\text { es el mayor día que el Cielo formó! }\end{array}$ & 50 \\
\hline TIEMPO & $\begin{array}{l}\text { ¿El Cielo y el Sol se pueden } \\
\text { engañar? No. ¿Luego yo } \\
\text { soy el engañado? Sí; } \\
\text { que es menor mal en rigor } \\
\text { confesar yo mi ignorancia } \\
\text { que culpar su perfección. } \\
\text { Mas, cielos, ¿cómo engañarme } \\
\text { puedo, cuando viendo estoy } \\
\text { en la brevedad del día } \\
\text { la prueba de mi opinión? } \\
\text { ¿No anda hoy el Sol tan apriesa } \\
\text { que da a entender que es mayor } \\
\text { el desdén del ausentarse } \\
\text { que de salir el favor? } \\
\text { Pues ¿cómo, contradiciendo } \\
\text { tan clara demostración, } \\
\text { se llama suyo, diciendo...? }\end{array}$ & 60 \\
\hline MúSICA & $\begin{array}{l}\text { ¡Suene mi voz, } \\
\text { que hoy es el más proprio día del Sol! }\end{array}$ & \\
\hline TIEMPO & $\begin{array}{l}\text { ¿No es hoy el día tan breve, } \\
\text { que se querella su autor } \\
\text { de que le ocupa la noche } \\
\text { su clara jurisdicción? } \\
\text { Pues ¿cómo le llama grande } \\
\text { con tan público pregón } \\
\text { el mismo Cielo, pues dice...? }\end{array}$ & 70 \\
\hline MúsıcA & $\begin{array}{l}\text { ¡Sepan que hoy } \\
\text { es el mayor día que el Cielo formó! }\end{array}$ & \\
\hline TIEMPO & $\begin{array}{l}\text { Pues ¿por qué, si el Sol y el Cielo } \\
\text { quisieron darle el blasón } \\
\text { de grande, no detuvieron, } \\
\text { para darle duración, } \\
\text { el uno el rápido giro, }\end{array}$ & 80 \\
\hline \multicolumn{3}{|c|}{$\begin{array}{l}\text { v. } 47 \text { blasón: «se toma, casi siempre, por el mismo escudo de armas» (Aut). Aquí en un uso metafó- } \\
\text { rico ya que el estribillo actúa como blasón o alabanza de la representación. } \\
\text { v. } 56 \text { perfección: no puede haber error en la creación, en cuanto obra de Dios. Por eso a pesar de la } \\
\text { contradicción de la existencia del día mayor, aunque en cuanto luz diurna que recibe sea más corto, el } \\
\text { Tiempo debe atribuir esa contradicción a su ignorancia. Ver n. anterior a v. 19. Ver Martínez, Repertorio, } \\
\text { p. 6: «Toda la máquina del universo mundo es semejante a un individuo, conviene a saber semejante a } \\
\text { una persona, y así como en el hombre no hay miembro, parte ni sentido que no sea útil y necesario para } \\
\text { la perfección y conservación de la vida, así en el cielo no hay parte ni estrella por mínima que sea que } \\
\text { no tenga su particular virtud e influencia, conveniente y necesaria para la perfección y permanencia de } \\
\text { todo el cuerpo del mundo». }\end{array}$} \\
\hline
\end{tabular}


o el otro el curso veloz?

¿Es buen término de honrar,

buen modo de dar honor,

contradecir las acciones

lo que acredita la voz,

si ya no es que hay en el día

algún oculto primor

que no alcanza mi discurso

ni penetra mi atención?

¿Quien hallaré que me alumbre

de tan ciega confusión

como padezco y tan graves

neutralidades?

(Por los dos lados salen el Cielo y el Sol y al salir dicen)

Cielo

Yo,

SOL

Yo,

CIELO

que te diré verdad, pues soy el Cielo!

SOL

que te podré alumbrar, pues soy el Sol!

TIEMPO

Soberanas deidades,

a quien estoy mirando,

depuesto tú lo excelso,

depuesto tú lo ardiente de tus rayos.

Si acaso mi descuido

os ofendió, pensando

que lo que en mi ignorancia,

en vosotros pudiera ser engaño

(por parecerme a algunos

que, neciamente vanos,

todo lo que no alcanzan

a comprender, condenan por errado),

sírvame de castigo

la vergüenza que paso,

pues a engaños del Tiempo

les es el mismo Tiempo desengaño;

y explicadme piadosos

la razón, que no alcanzo

qué es: ¿Por qué aqueste día

le publicáis mayor, sin ser más largo?

CiELO

(Cantando recitativo)

Óye, pues, la armonía

v. 96 neutralidades: «Indiferencia o indeterminación a uno de los extremos» (Aut).

v. 119 armonía: se trata de la música de las esferas. Ver n. al v. 161 de El divino Orfeo, primera parte, de donde tomo la nota. Los autores del XVII recogen las teorías desarrolladas por los filósofos griegos, los Padres de la Iglesia y algunos humanistas. Platón planteaba que la música de las esferas no era audible para los oídos humanos. Plotino defiende que la misma voz de Dios se oye como eco de la armonía 
que hacen con giros varios

mis orbes, que se mueven con giración, trepidación y rapto.

SOL

\author{
Del coro de mis musas \\ oye el sonoro canto \\ que explica los misterios \\ que mi sacra deidad ha revelado.
}

celestial. La idea llega hasta Bances Candamo, Teatro, p. 95: «No solamente han tenido los santos por armónica la fábrica de esos orbes cristalinos, sino su movimiento, asegurando entre otros [Cicerón] que si oyésemos aquella acorde música con que se mueven sus esferas, ensordeciéramos, y que por estar hecho desde el umbral de la vida aquel rumor sonoro [...] no le percibimos». Ver también Long, 2009, p. 87 , donde comenta esta loa.

v. 122 giración, trepidación y rapto: trepidación: «término astronómico. Movimiento que en el sistema de Ptolomeo y otros se da al cielo cristalino, con que casi insensiblemente y como temblando se mueve y mueve las demás esferas desde un polo a otro, discurriendo así para componer la variedad observada en las declinaciones de las estrellas fijas y puntos de la eclíptica» (Aut). Ver también movimiento de trepidación: «es el que hacen los orbes cristalinos de oriente a poniente y de mediodía a septentrión, como bamboleándose hacia estas partes. El cual, según los astrónomos, se imprime en toda la esfera y de él provienen varias irregularidades que observan en el movimiento natural de los astros según los mismos» (Aut). Ver movimiento rapto o violento: «Es aquel con que el sol, la luna y demás astros se mueven de levante a poniente, con el cual dan todos ellos cada día una vuelta al cielo. Llámase también movimiento diurno» (Aut). Suárez de Figueroa, Plaza universal de todas las ciencias y artes, vol. 2, pp. 537-532, explica estos tres movimientos: «Acerca del movimiento de la misma octava, donde están las estrellas fijas, combaten asimismo grandemente. Los astrólogos más modernos le dan un movimiento de tres suertes: el uno propio llamado trepidación, que se viene a cumplir en siete mil años; otro de giración de la nona esfera, cuya revolución no se acaba en menos de cuarenta y nueve mil años; el tercero, de la décima esfera que llamamos movimiento del primer móvil, o movimiento rapto o diurno, que vuelve cada día a su principio en término de un día natural». Macarte, Lecciones de navegación, p. 33: «En los astros o planetas se consideran tres movimientos: común, propio y de trepidación: el común, que también se llama rapto, violento o primero es el que los planetas y estrellas hacen de oriente en occidente en el tiempo de 24 horas. Movimiento propio, que también llaman segundo y natural, es el que ejecutan de occidente a oriente, en el cual no proceden con igualdad los planetas, porque unos andan más veloz que otros y aun un mismo planeta anda unas veces con más aceleración que otras. Movimiento de trepidación es aquel con que cualquiera planeta o astro se inclina hacia alguno de los polos».

v. 123 Del coro de mis Musas: porque el personaje es el Sol o Febo, como se le llama en el v. 210. Ver Pérez de Moya, Philosofía secreta, pp. 255-256: «Que las musas bailen al son de la lira que Apolo tañe en el monte Parnaso es que por Apolo se entiende el principio de toda sabiduría o dador de la sabiduría; y por la Musas, que son muchas, se entienden los que reciben el saber, los cuales no lo reciben todos, mas las partes que les dan. [...] En otro modo se puede esto entender, en cuanto Apolo significa el Sol, el cual y los demás planetas y cielos, entendidos por las Musas, se mueven con gran proporción; y porque el Sol tenemos todos los tiempos y se causa el día, mes y año, etc., que son tiempos y por el movimiento del Sol tenemos medida de todos los planetas y cuerpos celestiales, y a esto dicen bailar las Musas a su son, pues todos son conocidos por él, y dél reciben luz y resplandor. Tener esta lira de siete cuerdas denota los siete planetas, en medio de los cuales está el Sol, y porque según opinión de Pitágoras, el movimiento de los cielos causa música, por esto fue a Apolo o al Sol atribuida la música». Ver Grimal, Diccionario de mitología, p. 368: «Existían dos grupos principales de Musas: las de Tracia [...] y las de Beocia, a las que se ubicaba en las laderas del Helicón. [...] Las Musas del Helicón son colocadas bajo la dependencia directa de Apolo. Él dirige sus cantos en torno a la fuente de Hipocrene». 


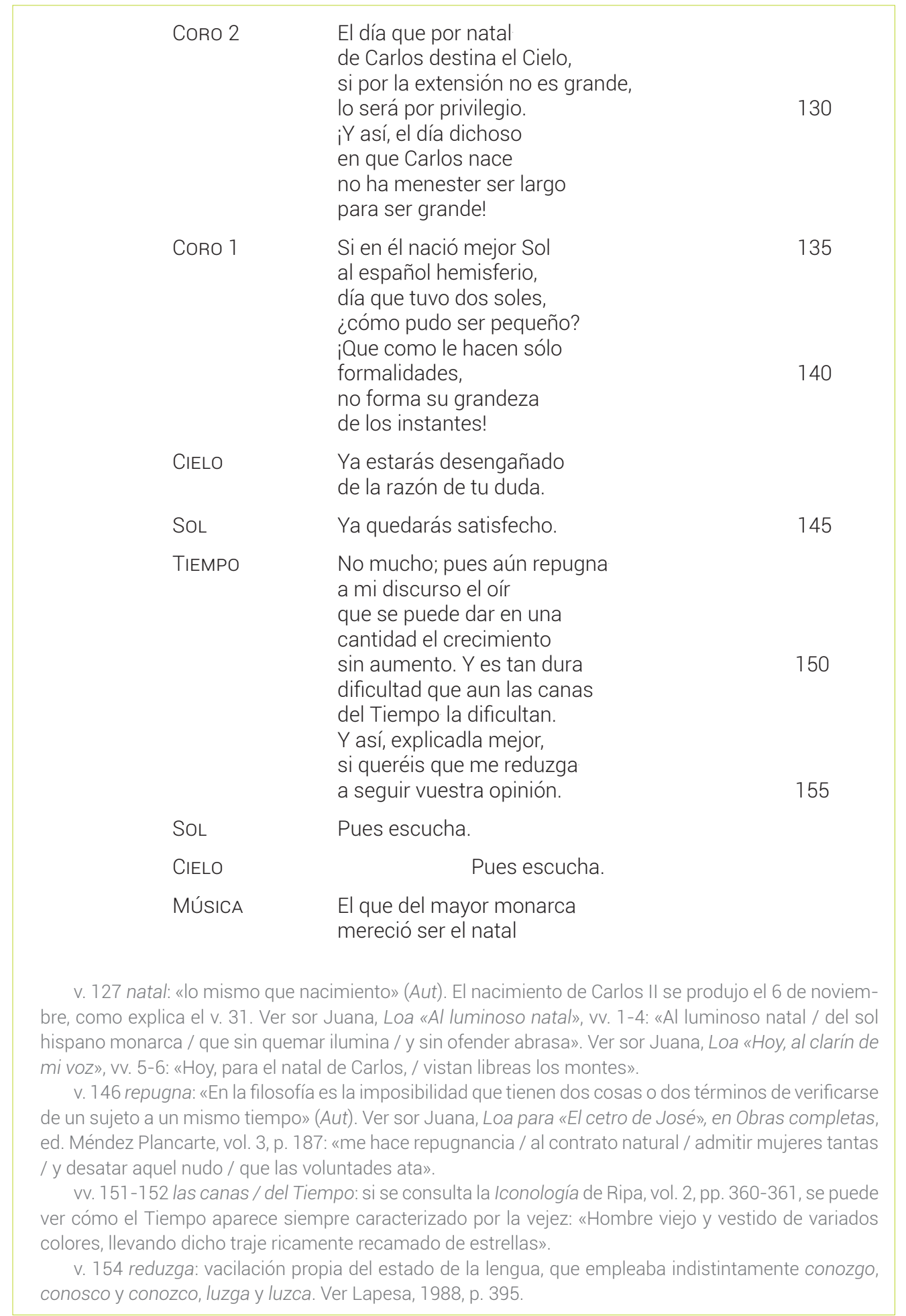




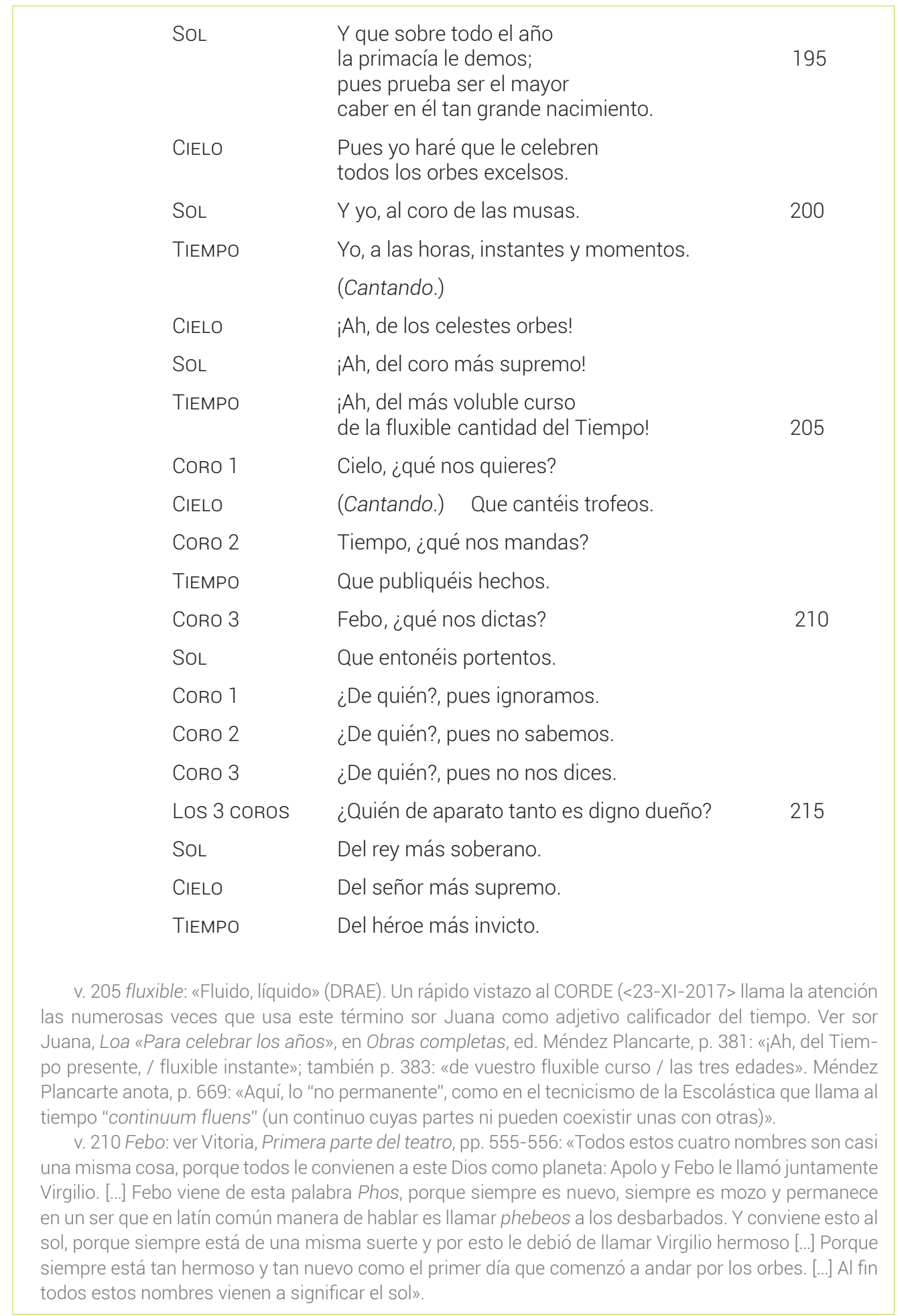




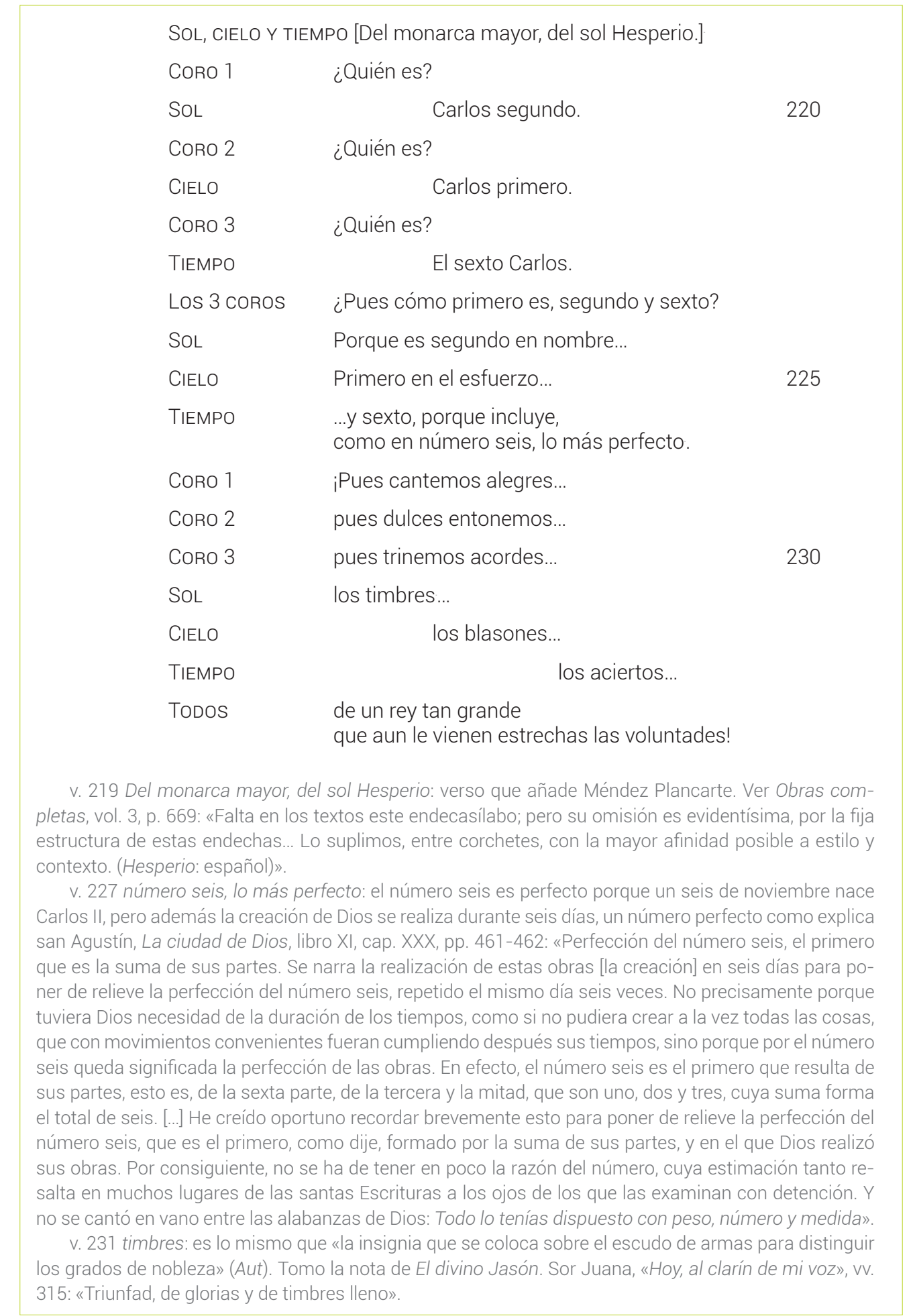




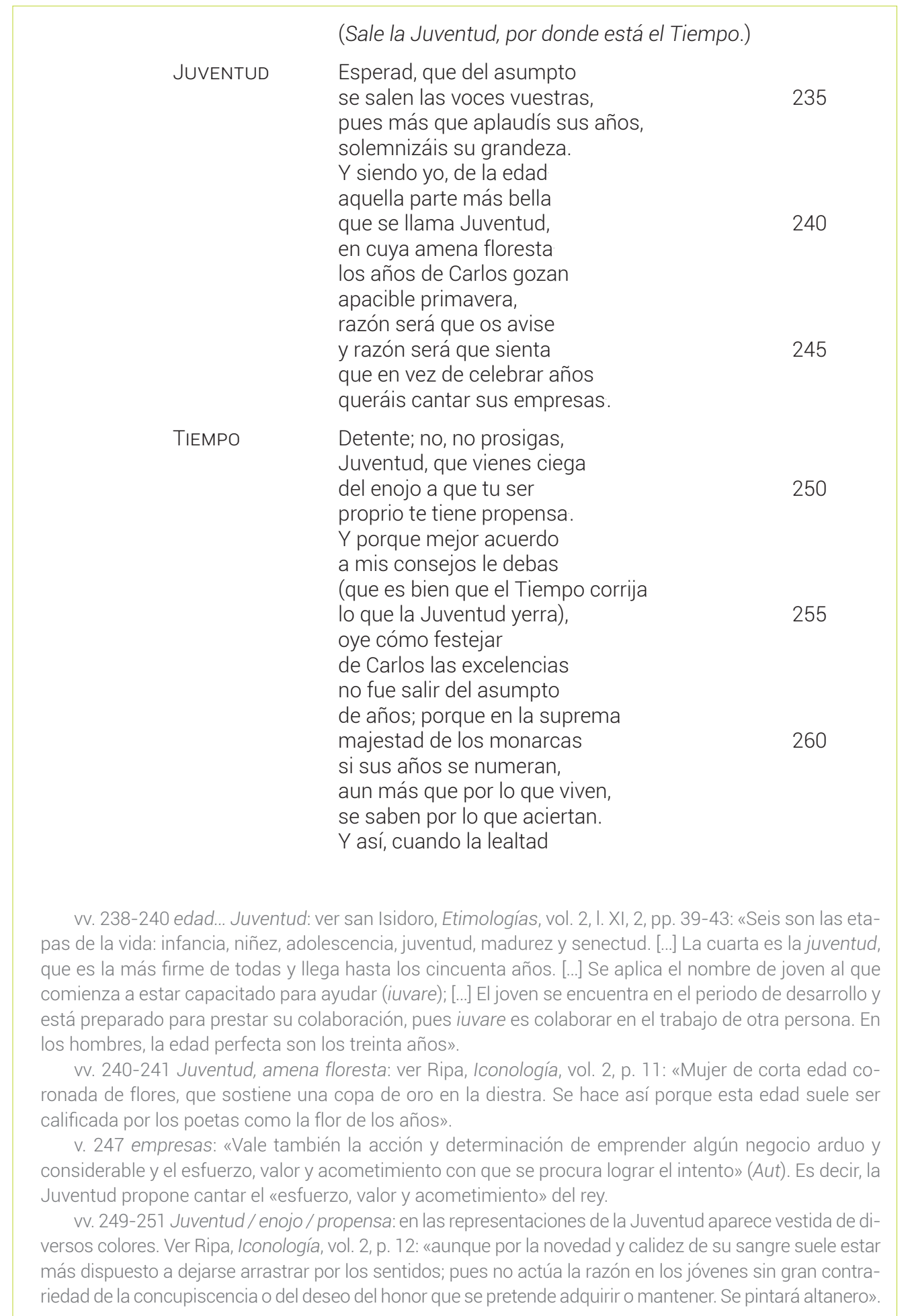


pues yo, que soy la Prudencia,

tan inseparable asisto

todas sus acciones regias,

tan niveladas las mido

que en su dorada madeja

admira el acierto canas

el que Ofir el Tiempo peina.

ELLA Y LA MúsICA ¡Que el que del común orden

se mira esempto,

no ha menester los años

para ser cuerdo!

(Sale la Felicidad, por donde está el Cielo.)

FELICIDAD

Pues si no ha menester años

una Juventud tan cuerda,

que las experiencias logra

sin pasar las experiencias,

y siendo de sus acciones

asesora la Prudencia,

de razón le ha de seguir

la Felicidad; que es fuerza

que, si la Prudencia manda,

la Felicidad suceda.

Y así yo, que lo soy, vengo,

como la más propia herencia

de Carlos, a festejar

sus años, en consecuencia...

ELLA Y LA MúsICA ¡De que la suerte asiste,

como precisa,

al que de sus aciertos

labra sus dichas!

TIEMPO

Pues a los felices años del mayor monarca asisten el Cielo, que los aumente,

vv. 294-295 Ofir: es el nombre de un país nombrado en la Biblia como productor de oro fino, al parecer situado al norte del golfo de Arabia. La mención más conocida es a la flota que armó Salomón (1 Reyes, 9, 26-28) que funciona como metonimia del oro y las riquezas (tomo la nota de El nuevo hospicio de pobres de Calderón, v. 292). Canas / el que ofir el Tiempo peina: este pasaje lo comenta García Valdés, 2010, pp. 176-177: «El Acierto admira la prudencia propia de la vejez, simbolizada en el término 'canas', en el dorado cabello, representado por Ofir, metáfora usual por el oro, que el Tiempo aún joven peina -el rey contaba en ese momento con veinte años-». Encontramos una referencia a un verso de la Biblia en Sabiduría, 4, 8-9: «Que a honrada vejez no es la de muchos años, ni se mide por el número de días. La prudencia es la verdadera canicie del hombre». Ver García Valdés, 2010, p. 176: «En las cinco que dedica al rey Carlos II con motivo de su cumpleaños reitera sor Juana una agudeza paradójica entre la "juventud florida" y la "cana prudencia" que adornan al monarca tomada del Libro de la Sabiduría (4, 7-9 y 13), donde se afirma que la honrada vejez no es la de muchos años, ni se mide por el número de días; sino que en la prudencia está la canicie y la verdadera ancianidad es una vida sin mancha». Ver sor Juana, Loa «Aunque de la vida son», v. 59: «la adorna cana prudencia». 
el Sol, que los ilumine,

el Tiempo, que los conserve,

la Prudencia, que los guíe,

la Juventud, que los logre,

la Dicha, que los sublime...

ÉL Y LA MúsICA ¡Rogad todos alegres,

pedid humildes

al Cielo que le guarde

años felices

y con ecos alegres de aclamación festiva

decid que nuestro gran Monarca viva, viva!

SOL

Los años de tal monarca

que el Cielo de rayos viste,

no los cuenta por costumbre:

por vanidad los repite.

Cielo

Los dilatados espacios

de la eternidad registre,

derogándose en su edad

la ley de los imposibles.

Prudencia Siendo estudio de las luces,

si el Sol de sus rayos vive,

por ceremonia del Tiempo

sin ser suyos se permiten.

FELICIDAD No es desaire al noble intento no alcanzar los imposibles;

que augustas celebraciones se intentan, no se consiguen.

JUVENTUD Los años de que hace gala la edad que en Carlos asiste, de la color del respeto la veneración los tiñe.

TIEMPO

En sus repetidas horas, constantes y siempre firmes, cuando las confunda el Tiempo, lo eterno las averigüe.

Prudencia Tened los sonoros ecos;

que no es bien que se os olvide aclamar la siempre excelsa, soberana, alta, plausible, digna consorte de Carlos,

v. 350 la color del respeto: entiendo 'el color blanco de la canicie'

v. 359 plausible: «lo que es digno y merecedor de aplauso» (Aut).

v. 360 digna consorte de Carlos: se trataba de la reina María Luisa de Orleáns, sobrina de Luis XIV, primera esposa de Carlos II, con quien se casa en 1679 y de la que enviudará en 1689. Ver sor Juana, Loa «Aunque de la vida son», vv. 421-424: «Y pues la francesa / Flor de Lis divina, / que trasplantó a España / su pompa florida». 


\begin{tabular}{|c|c|c|}
\hline & $\begin{array}{l}\text { que en vínculo une felice } \\
\text { a los blasones de España } \\
\text { sus siempre gloriosas Lises. } \\
\text { Y pues es bien que también } \\
\text { el obsequio participe... }\end{array}$ & 365 \\
\hline MúSICA & \multicolumn{2}{|l|}{$\begin{array}{l}\text { ¡Rogad todos, alegres; } \\
\text { pedid, humildes, } \\
\text { al Cielo que los guarde } \\
\text { años felices! }\end{array}$} \\
\hline Cielo & $\begin{array}{l}\text { Decoro, no olvido, fue } \\
\text { ese, de la atención lince, } \\
\text { pues siendo los dos tan uno, } \\
\text { que en vínculo indivisible, } \\
\text { un cuerpo hospeda dos almas } \\
\text { o una alma dos cuerpos rige. } \\
\text { Y pues la excelsa María } \\
\text { y nuestro gran Carlos viven } \\
\text { tan uno que no le dejan } \\
\text { a la atención que averigüe } \\
\text { si quiere Amor que se unan } \\
\text { o hace que se identifiquen, } \\
\text { no fuera acertada acción } \\
\text { que, en lo que no es divisible, } \\
\text { prescindir quiera el obsequio } \\
\text { lo que el Amor no prescinde. } \\
\text { Y así, pues aqueste corto } \\
\text { obsequio que Amor le rinde, } \\
\text { es fuerza que a María llegue } \\
\text { cuando a Carlos se dirige... }\end{array}$ & 375 \\
\hline MúSICA & $\begin{array}{l}\text { ¡Rogad todos, alegres; } \\
\text { pedid, humildes, } \\
\text { al Cielo que los guarde } \\
\text { años felices! }\end{array}$ & 390 \\
\hline FELICIDAD & $\begin{array}{l}\text { Otro no menor olvido, } \\
\text { pues de ése tan bien saliste, } \\
\text { hay, Cielo; y es que no has dado }\end{array}$ & 395 \\
\hline \multicolumn{3}{|c|}{$\begin{array}{l}\text { v. } 363 \text { Lises: «insignia con que se adorna el escudo de armas de Francia que son tres lirios, porque } \\
\text { en aquella lengua se llama lis esta flor» (Aut). } \\
\text { v. } 371 \text { lince: «animal de aguda vista, que algunos llaman lobo cerval» (Cov.). } \\
\text { vv. } 373-375 \text { vínculo indivisible: porque la unión de los dos monarcas se produce a través del matri- } \\
\text { monio y este es indivisible. Ver Canisio, Suma de doctrina, pp. 111-113: «Es un ayuntamiento legítimo de } \\
\text { varón y de la mujer [...] la cual no se puede deshacer durante la vida de entrambos [...]. Aunque no haya hijos } \\
\text { entre ellos, y suceda cualquier adversidad y trabajo por grande y adverso que sea, vale todavía el matrimo- } \\
\text { nio; y es tan firme y tan indivisible después que está consumado, que mientras dura a entrambos, quedan } \\
\text { atados sin que pueda entrar entre ellos división alguna». Ver Carranza, Comentarios, vol. 3, p. 508: «[el } \\
\text { matrimonio] trae consigo un vínculo indisoluble, si no es con solo la muerte de el uno de los casados». Un } \\
\text { cuerpo hospeda dos almas: se trata de una referencia al texto evangélico relativo al matrimonio: «Por eso } \\
\text { dejará el hombre al padre y a la madre y se unirá a su mujer y serán los dos una sola carne» (Mateo, 19, 5). }\end{array}$} \\
\hline
\end{tabular}




\begin{tabular}{|c|c|c|}
\hline \multirow[b]{2}{*}{ PRUDENCIA } & \multicolumn{2}{|l|}{$\begin{array}{l}\text { quien a sus influjos puede } \\
\text { hacer que se multipliquen. }\end{array}$} \\
\hline & $\begin{array}{l}\text { Y este senado, de tanto } \\
\text { grave Licurgo, acredite } \\
\text { con obsequio reverente } \\
\text { la obligación que le asiste. }\end{array}$ & 430 \\
\hline FELICIDAD & $\begin{array}{l}\text { Y la ciudad, que gozando } \\
\text { de noble el más alto timbre, } \\
\text { el padrón de esta memoria } \\
\text { en la eternidad escribe. }\end{array}$ & 435 \\
\hline JUVENTUD & $\begin{array}{l}\text { Las damas celebren años, } \\
\text { de que ignoran lo fluxible; } \\
\text { pues años en las deidades } \\
\text { se aplauden, mas no se imprimen. }\end{array}$ & 440 \\
\hline TIEMPO & $\begin{array}{l}\text { Y porque el real asumpto } \\
\text { que a esta aclamación plausible } \\
\text { le dio felices principios, } \\
\text { le dé venturosos fines... }\end{array}$ & \multirow[t]{5}{*}{445} \\
\hline CORO 1 & \multirow[t]{4}{*}{ ¡Pedid todos, alegres; rogad, humildes... } & \\
\hline CoRo 2 & & \\
\hline CORO 3 & & \\
\hline LOS 3 coROs & & \\
\hline \multicolumn{3}{|c|}{$\begin{array}{l}\text { v. } 430 \text { senado: 'público'. «Se toma por cualquier junta o concurrencia de personas graves, respeta- } \\
\text { bles y circunspectas» (Aut). Ver Loa «Si la tórrida», vv. 446-448: «Viva el senado glorioso, / que lo severo } \\
\text { y piadoso / junto ha sabido obtener». } \\
\text { v. } 431 \text { Licurgo: «Ciudadano noble de Sparta, hijo de Polidecta y hermano de Eunomo, rey de Lacede- } \\
\text { monia. [...] Hizo leyes justas y santas» (Cov.). Vitoria, Primera parte, p. 242: «El séptimo rey de la familia } \\
\text { de Euristeo fue Agesilao, primero deste nombre, en cuyo tiempo floreció Licurgo, el legislador. El cual, } \\
\text { después de haber dado leyes a este reino, les pidió palabra que las guardasen hasta que él volviese de } \\
\text { consultar el oráculo cerca dellas. Y sabiendo del que no las habían quebrantado, determinó de no volver } \\
\text { más a su patria y así se mató porque no le obligasen a volver». Ver sor Juana, Loa «Aunque de la vida } \\
\text { son», vv. } 453-456 \text { : «Y el senado que es, / en paz y justicia, / de Minos afrenta, / de Licurgo envidia». } \\
\text { v. } 436 \text { padrón: «columna de piedra, con una lápida o inscripción de alguna cosa que conviene que } \\
\text { sea perpetua y pública». Ver sor Juana, Loa para el auto intitulado "El mártir del sacramento", en Obras } \\
\text { completas, ed. Méndez Plancarte, vol. 3, pp. 104-105: «Sirviendo a su nombre / de padrón eterno, / las } \\
\text { columnas que / respetará el tiempo». }\end{array}$} \\
\hline
\end{tabular}


VARIANTES «ESCUCHE MI VOZ EL ORBE»

\section{Testimonios}

SV: Segundo volumen de las obras de soror Juana Inés de la Cruz, monja profesa en el monasterio del señor san Gerónimo de la ciudad de México, Sevilla, por Tomás López de Haro, 1692, pp. 351-360. Biblioteca digital hispánica: <http://bdh.bne.es/bnesearch/CompleteSearch.do?field=todos\&text=So $r+J u a n a+\ln \% c 3 \% a 9 s+d e+l a+C r u z \& s h o w Y e a r l t e m s=\&$ exact $=0 n \& t e x t H=$ \&advanced=false\&completeText $=\&$ pageSize $=1$ \&pageSizeAbrv=30\&page Number $=13>(6-11-2017)$

ST: Segundo tomo de las obras de soror Juana Inés de la Cruz, monja profesa en el monasterio del señor san Gerónimo de la ciudad de México, anadido de esta segunda impresión por su autora, Barcelona, Joseph Llopis, 1693, pp. 275-284.

OP. Obras poéticas de la musa mexicana soror Juana Inés de la Cruz, religiosa profesa en el monasterio del gran Padre y doctor de la Iglesia S. Gerónimo de la ciudad de México, Madrid, Imprenta Real, 1715, pp. 275-284. Biblioteca digital hispánica: <http://bdh.bne.es/bnesearch/CompleteSearch. do?field=todos\&text=Sor+Juana+In\%c3\%a9s+de+la+Cruz\&showYearlte $\mathrm{ms}=\&$ exact $=$ on\&text $\mathrm{H}=\&$ advanced $=$ false $\&$ completeText $=$ \&pageSize $=1 \&$ pageSizeAbrv=30\&pageNumber $=11>(6-11-2017)$.

E8: Segundo tomo de la obras de soror Juana Inés de la Cruz, monja profesa en el monasterio del señor san Gerónimo de la ciudad de México, Madrid, Imprenta de Angel Pascual Rubio, 1725, pp. 255-264.

MP. Loa a los años del Rey (III) (376), en Obras completas de Sor Juana Inés de la Cruz, ed. A. Méndez Plancarte, México, Fondo de Cultura Económica, 1955, vol. 3, pp. 313-330.

\section{Variantes}

$1 \quad$ MP introduce acotación: Escena I

6 proprio día del sol] propio día del sol MP

$40 \quad$ Música y Sol] Música MP

41 el mas proprio día] el más propio día MP; el mas propia dia OP

46 no lo corrige] no le corrija SV, ST, OP, E8

48 del día repite] del día repita SV, ST, OP, E8

54 menor mal] menos mal SV, ST, OP

67 se llama] lo llama MP

69 proprio día] propio día MP

74 le llama] lo llama MP

96 MP introduce acotación: Escena II

102 depuesto tú lo ardiente] despuesto tú lo ardiente MP

105 que lo que en] que en lo que en ST

118 le publicáis] lo publicáis MP

132 en que Carlos] que Carlos MP

139 le hacen solo] lo hacen solo MP

142 MP introduce acotación: Escena III

152 la dificultan] las dificultan SV, ST, OP, E8 
154 reduzga] reduzca MP

180 que eso será] que esto será OP

198 que le celebren] que lo celebren MP

201 MP introduce acotación: Escena IV

219 Del mayor monarca, del sol Hesperio] omite SV, ST, OP, E8

227 como en número] como el número MP

233 MP introduce acotación: Escena $\mathrm{V}$

234 que del asumpto] que del asunto MP

251 proprio] propio MP

253 consejos le debas] consejo les debas MP

258 del asumpto] del asunto MP

271 MP introduce acotación: Escena VI

294 el acierto canas] el acierto cauas OP

297 esempto] exento MP

299 MP introduce acotación: Escena VII

317 MP introduce acotación: Escena VIII

333 que el Cielo] que al Cielo ST

344 al noble] el noble SV, ST, OP, E8

374 hospeda dos almas] hospeda a dos almas MP

375 o una alma] o un alma MP

395 de ese tan bien saliste] de ese tambien saliste OP

442 el real asumpto] el real asunto MP

449 gran monarca viva, viva] gran monarcha viva, viva, viva SV, ST, OP, E8 